\title{
REVIEW
}

\section{The Potential of Using Bee Pollen in Cosmetics: a Review}

\author{
Xiaozhi $\mathrm{Xi}^{1}$, Jia $\mathrm{Li}^{1}$, Shasha Guo ${ }^{2}$, Yujuan $\mathrm{Li}^{1}$, Fangxue $\mathrm{Xu}^{1}$, Mengmeng Zheng ${ }^{1}$, \\ Hui Cao", Xiaowei Cui ${ }^{1}$, Hong Guo ${ }^{1}$, and Chunchao Han ${ }^{1 *}$ \\ ${ }^{1}$ School of Pharmacy, Shandong University of Traditional Chinese Medicine, Jinan 250355, People's Republic of CHINA \\ ${ }^{2}$ School of Traditional Chinese Medicine, Shandong University of Traditional Chinese Medicine
}

\begin{abstract}
During ancient times in China, bee pollen was used for skin whitening and beauty. Around $\mathbf{7 0 \%}$ of substances in bee pollen are biologically active, such as proteins, carbohydrates, lipids and fatty acids, phenolic compounds, vitamins and bioelements.

This review describes the cosmeceutical properties of bee pollen and the mechanism of its active components action, its beneficial influence on human skin. As a natural bee product, bee pollen may effectively enhance protective mechanisms against skin aging, skin dryness, ultraviolet $B$ radiation, oxidative damage, inflammatory and melanogenesis, which are involved in a wide range of negative effects on human skin, thus they have attracted attention for health and cosmetic applications.
\end{abstract}

Key words: bee pollen, active ingredients, cosmetics

\section{Introduction}

Bee pollen is the pollen cluster that the honeybee brings back when collecting honey. The pollen formed after storage and fermentation in the hive. It was formed by mixture of flower pollen from different species agglutinated by nectar and honeybee enzymes (e.g. amylase, catalase) secreted by salivary glands and pollen-loads ${ }^{1)}$. It plays an important role in the treatment of diseases in ancient Chinese medicine. For thousands of years, the health and medicinal properties of bee pollen have been used up to now $^{2)}$. It demonstrates a series of actions such as antioxidant, anti-inflammatory, anti-carcinogenic, anti-bacterial, anti-fungicidal, hepatoprotective, and anti-atherosclerotic activities capable of modifying or regulating immune functions (Table 1).

During ancient times in China, bee pollen was used for skin whitening and beauty. There are many chemical constituents in bee pollen, which has great potential for development in the cosmetics field. Such as, proteins, amino acids, carbohydrates, lipids, fatty lipids, phenolic compounds, vitamins and bioelements. Amino acids consist of methionine, lysine, threonine, histidine, leucine, isoleucine, valine, phenylalanine, and tryptophan. Carbohydrates consist of fructose, glucose, sucrose, fibre. Fatty acids consist of linoleic, $\gamma$-linoleic, and archaic. Phenolic compounds include flavonoids, leukotrienes, catechins, and phenolic. Vitamins such as provitamin A( $\beta$-carotene), vitamin $\mathrm{E}$ (tocopherol), niacin, thiamine, biotin and folic acid, enzymes or co-enzymes. And bioelements include $\mathrm{Ca}$, $\mathrm{Mg}, \mathrm{Fe}, \mathrm{Zn}, \mathrm{Cu}$, with a high $\mathrm{K} / \mathrm{Na}$ ratio (Table 2). A number of these secondary metabolites derived from plant are known for their benefits to the skin. The metabolites are used in skin protection such as skin whitening, moisturization, free-radical scavenging, anti-inflammatory, antiaging effects. These effects have provided beneficial support for the development of bee pollen in the field of cosmetics.

\section{Phytochemicals to cosmetics}

2.1 Proteins of bee pollen in cosmetics

2.1.1 Cosmetic and skin care protein derivatives

Many biological reactions of proteins play a vital role in the body. Environmental pollution, ultraviolet(UV) radiation, microorganisms and viruses, these exogenous or environmental-derived free radicals may cause premature aging and aging of the skin. The current study found that wrinkles, senile plaques, and dry skin may be related to im-

\footnotetext{
*Correspondence to: Chunchao Han, School of Pharmacy, Shandong University of Traditional Chinese Medicine, Jinan 250355, People's Republic of CHINA

E-mail: chunchaoh@126.com

Accepted May 7, 2018 (received for review March 22, 2018)
}

Journal of Oleo Science ISSN 1345-8957 print / ISSN 1347-3352 online

http://www.jstage.jst.go.jp/browse/jos/ http://mc.manusriptcentral.com/jjocs 
Table 1 Potential therapeutic properties of bee pollen and plausible biological mechanisms.

\begin{tabular}{|c|c|}
\hline Therapeutic properties & Plausible biological mechanisms ${ }^{\text {ref.) }}$ \\
\hline Anti-inflammatory & $\begin{array}{l}\text { 1. Activation of numerous cells (macrophages, T cells, B cells, NK cells, hepatocytes, mast cells, } \\
\text { basophils, neutrophils, eosinophils) } \downarrow^{3,4)} \\
\text { 2. Arachidonic acid metabolism } \downarrow \text {, the level of proinflammatory prostaglandins } \downarrow^{5,6} \\
\text { 3. Protein phosphorylation } \downarrow \text {, modify cell signaling pathways } \\
\text { 4. Proinflammatory NF- } \kappa \text { B pathway } \downarrow^{\text {5) }} \\
\text { 5. Cyclooxygenase and lipoxygenase } \downarrow^{8)} \\
\text { 6. Enzymes(Turning arachidonic acid into toxic compounds) } \downarrow^{8)}\end{array}$ \\
\hline Anti-oxidative & $\begin{array}{l}\text { 1. ROS } \downarrow^{9,10)} \\
\text { 2. Inactivation of electrophiles, free radicals } \downarrow^{4}\end{array}$ \\
\hline Anti-carcinogenic & $\begin{array}{l}\text { 1. ROS } \downarrow^{4)} \\
\text { 2. Inactivation of oxygen reactive species } \\
\text { 3. Apoptosis } \uparrow^{12)} \\
\text { 4. TNF- } \alpha \uparrow^{12)}\end{array}$ \\
\hline Anti-bacterial, Anti-fungal & 1. Cytoplasm membrane degradation ${ }^{13)}$ \\
\hline Anti-allergenic & $\begin{array}{l}\text { 1. Ig M and IgG } \uparrow^{14)} \\
\text { 2. Activation of mast cells } \downarrow \text {, histamine } \downarrow^{15)} \\
\text { 3. Ig E binding to FceRI } \downarrow^{15)} \\
\text { 4. Histamine secretion } \downarrow^{15)}\end{array}$ \\
\hline Anti-atherosclerotic & $\begin{array}{l}\text { 1. Total lipids } \downarrow \text {, Triacylglycerol } \downarrow^{16,17)} \\
\text { 2. Platelet aggregation } \downarrow^{18)} \\
\text { 3. Fibrinolytic activity } \uparrow^{18)} \\
\text { 4. Cholesterol } \downarrow^{19)}\end{array}$ \\
\hline Hypolipidemic & $\begin{array}{l}\text { 1. Plasma total lipids } \downarrow^{20)} \text {, Triacylglycerols } \downarrow^{21)} \\
\text { 2. Lipid correlated hormons (e.g. insulin, testosterone, thyroxine) } \downarrow^{22)}\end{array}$ \\
\hline Detoxifying & $\begin{array}{l}\text { 1. Pathological levels of enzymes Enzymes(e.g. alanine and aspartate transaminase, acid } \\
\text { phosphatase, and bilirubin) } \downarrow^{20)} \\
\text { 2. Bilirubin } \downarrow^{20)}\end{array}$ \\
\hline Dietary supplement & $\begin{array}{l}\text { 1. Vitamin } C \text { and magnesium } \uparrow^{23-25)} \\
\text { 2. Hemoglobin content and red blood cells } \uparrow^{23-25)} \\
\text { 3. Protein metabolism regulation and enhancement }{ }^{12)}\end{array}$ \\
\hline
\end{tabular}

Table 2 Bee pollen composition and content.

\begin{tabular}{lrl}
\hline \multicolumn{1}{c}{ Chemical composition } & Content & \multicolumn{1}{c}{ Main components $^{\text {ref.) }}$} \\
\hline Carbohydrates & $30.8 \%$ & Reducing sugars (e.g. fructose, glucose) ${ }^{26}$ \\
Proteins & $22.7 \%$ & Essential amino acids, nucleic acids (e.g. ribonucleic) ${ }^{27-29)}$ \\
Lipids & $5.1 \%$ & Essential fatty acids, Phospholipids, Phytosterols (e.g. P-sitosterol) \\
Polyphenolics & $1.6 \%$ & Flavonoids, leukotrienes, catechins, and phenolic acids ${ }^{31)}$ \\
Vitamins & $0.7 \%$ & Provitamin A, Vitamin $\mathrm{B}_{1}, \mathrm{~B}_{2}, \mathrm{~B}_{6}$, and C, Vitamin E and D and acids ${ }^{27,28,32,33)}$ \\
Bioelements & $1.6 \%$ & Macronutrients $(\mathrm{Ca}, \mathrm{P}, \mathrm{Mg}, \mathrm{Na}, \mathrm{K})$ and Micronutrients $(\mathrm{Fe}, \mathrm{Cu}, \mathrm{Zn}, \mathrm{Mn}, \mathrm{Si}, \mathrm{Se}){ }^{27,28,32,33)}$ \\
\hline
\end{tabular}

balances in the body of the protein ${ }^{32)}$. Surfactants are an important component of cosmetics and they are an integral part. However, prolonged skin contact with surfactants can cause side effects. The main mechanism of action is that the surfactant molecules denature the stratum corneum of the skin and cause skin damage. Based on this, the addition of protein derivatives to cosmetics to complex with surfac- tants (Fig. 2) may have a role in preventing the surfactant from entering the dense mesh of keratin fibers ${ }^{33,34)}$.

Most of the skin care products use a substance rich in protein, which can promote the ability of water to combine with the cuticle skin and its appendages, and play a role in skin whitening ${ }^{35)}$. In recent years, it has been found that protein derivatives can also be used in various skin care 


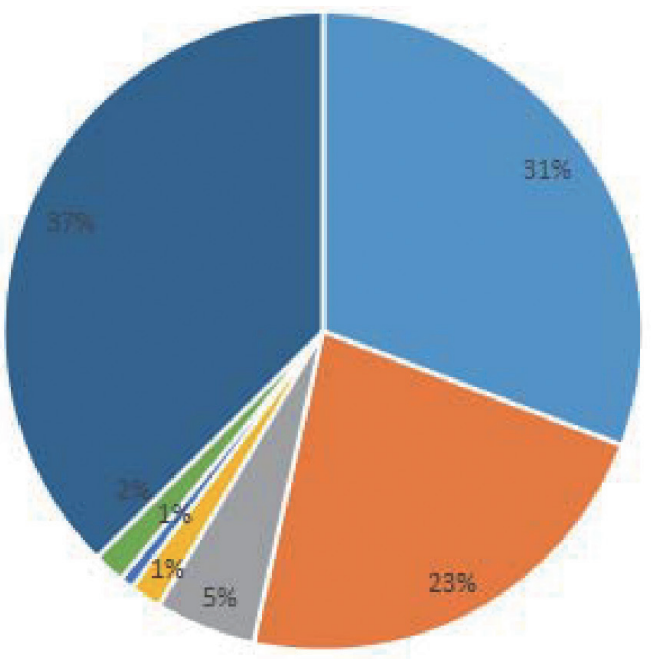

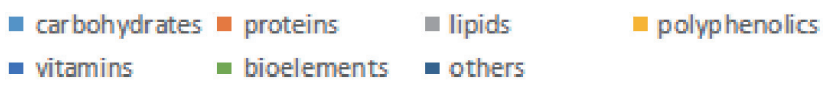

Fig. 1 The ratio of compositions in bee pollen.

and cosmetic formulations. Studies have found that soluble protein derivative ingredients are suitable for almost all types of cosmetic forms (emulsions, lotions and gels, etc.). Other studies have shown that protein derivatives used for cosmetic purposes are obtained from simple proteins that can be easily obtained from lower organisms (algae, fungi), eliminating many complicated procedures ${ }^{36)}$. As mentioned in the review, the use of protein in bee pollen has great potential for development in cosmetics.

\subsubsection{Amino acids in cosmetics}

Protein hydrolyzed small molecule substances are used by most cosmetics. Natural proteins produce 20 basic proteins after hydrolysis, and their spatial structure and sequence determine their biological properties. Numerous studies have found that protein diets rich in amino acids that are well-balanced can help maintain beautiful skin. UV irradiation is the main culprit implicated in premature skin aging, which is referred to as photoaging. They are capable of inducing aging-related changes even in the dermis, partly due to their greater average depth of skin penetration $^{37)}$. A large number of studies have shown that intracellular MAAs can provide effective protection for radiationsensitive organisms ${ }^{38)}$. Some MAAs may protect the cell not only against UV radiation by absorbing the high-energy photons and dissipating the energy as heat but also by scavenging reactive oxygen species such as singlet oxygen, superoxide anions, hydroperoxyl radicals, and hydroxyl radicals. Chiaki Oyamada et $a l .{ }^{39)}$ examined the protective effects of the three MAAs on human fibroblast cells from UV irradiation ${ }^{40)}$. Currently detectable (MAA) in amino acids have been shown to have a role in preventing UV radiation-induced apoptosis.. Amino acids can prevent the accumulation of melanin and can effectively prevent ultraviolet rays from damaging the skin and achieve skin care (Fig. 3)

On the other hand, the stratum corneum on the surface of the skin maintains moisture in the skin. Among them, the natural moisturizing factor (NMF) is an important ingredient for keeping moisture. NMF is mainly composed of fi-

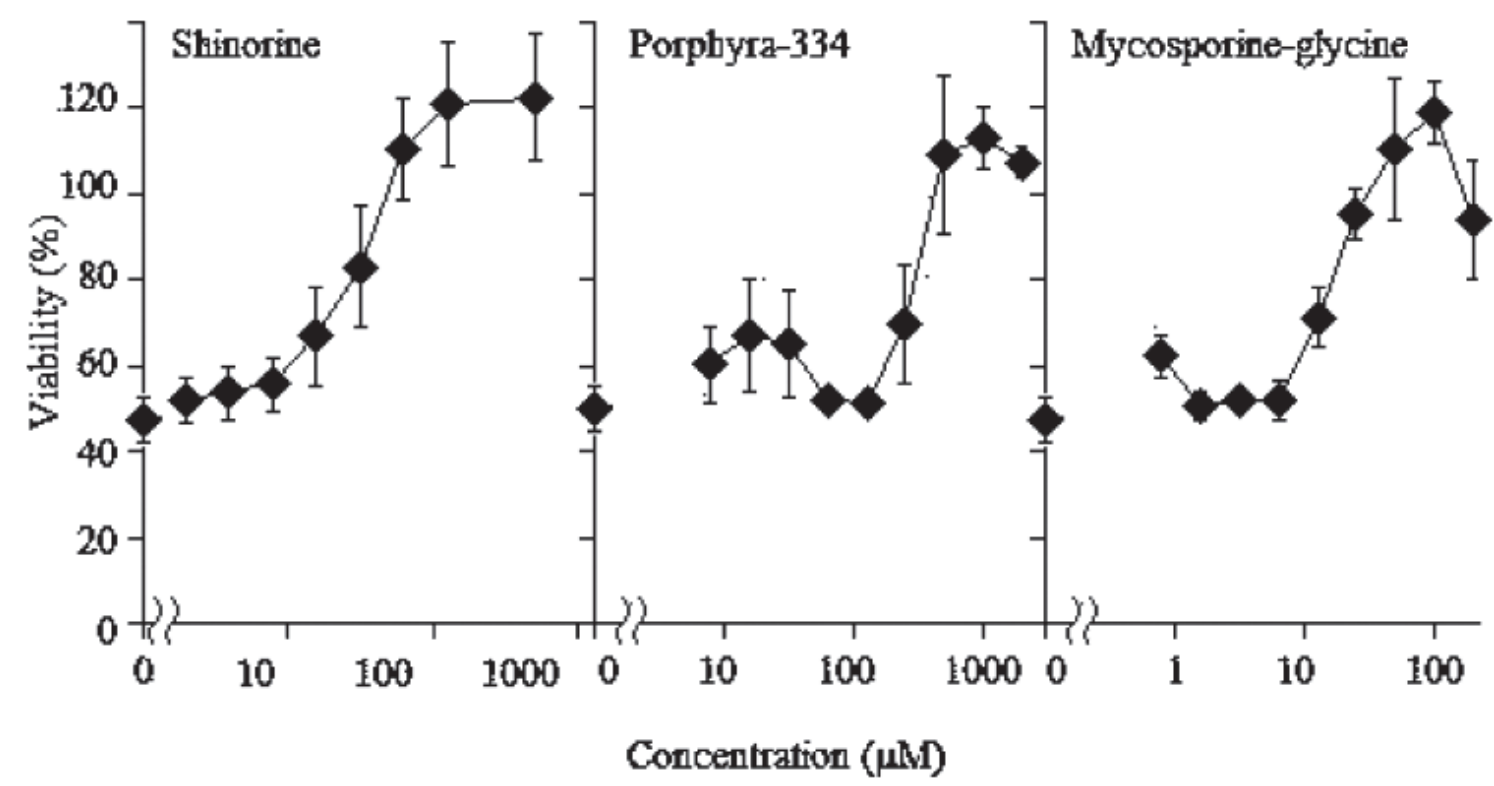

Fig. 2 The presence or absence of mutanase-like amino acids (MAAs) (shinorine, porphyra-334, and mycosporineglycine) for $24 \mathrm{~h}$ were reduced from $100 \%$ to approximately $50 \%$ due to the UV-treated.. And the viability of none-UVtreated cells (absence of MAAs) was indicated as $100 \%$. As a whole, the shinorine's viability is beeter than the others $^{33,34)}$. 


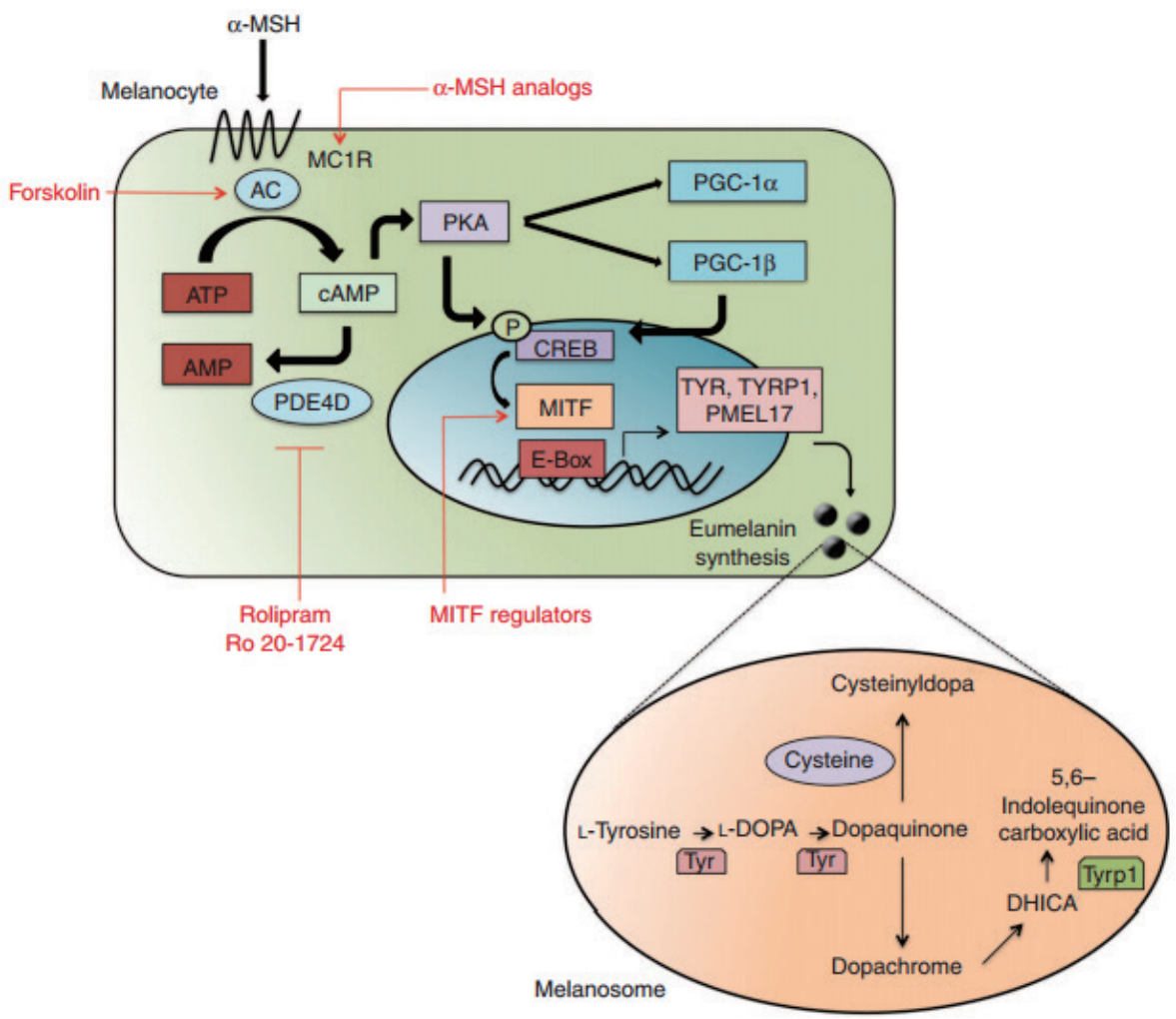

Fig. 3 Amino acids regulate the tanning response ${ }^{40)}$.

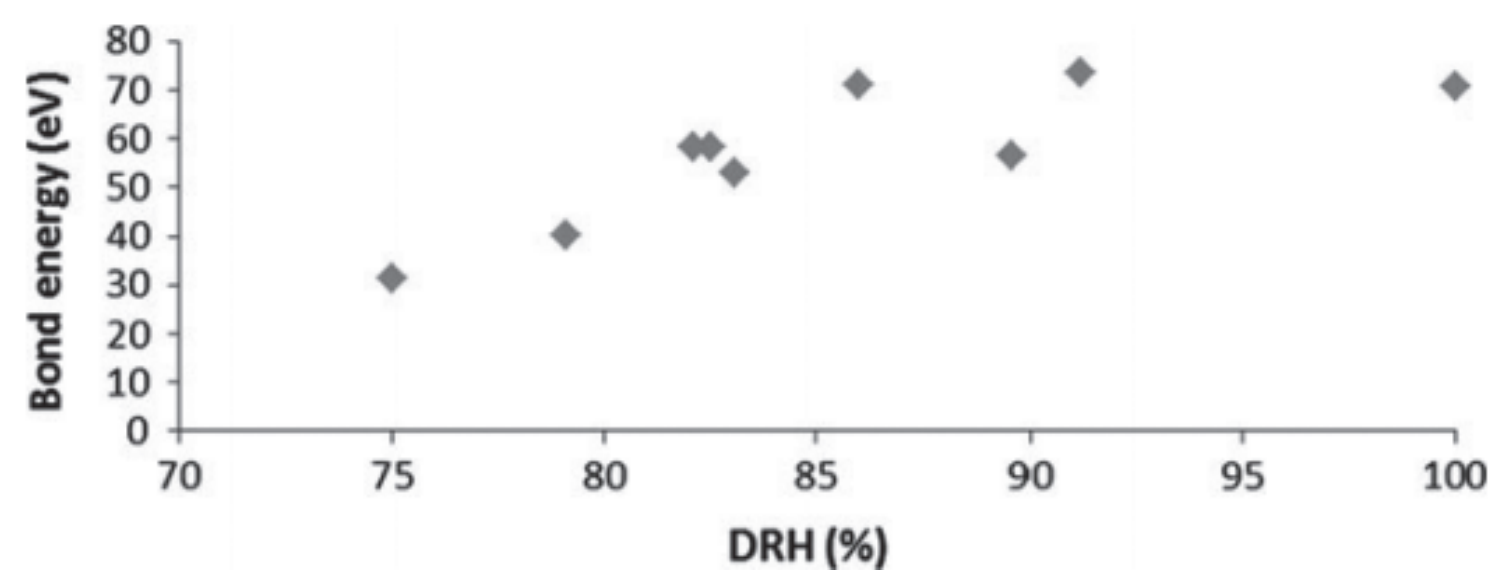

Fig. 4 A graph showing experimental bond energy for natural amino acids (and urea) against their experimental deliquescence relative humidity $(\mathrm{DRH})^{43}$. From left to right: urea, glycine, D-serine, L-serine, L-alanine, L-threonine, L-cysteine, L-asparagine, L-aspartic acid.

brin-derived free amino acids, which also provides a basis for the application of this protein derivative in skin care ${ }^{41}$. In addition, L-serine is the most abundant ( $\sim 36 \%)$ followed by glycine (22\%) and L-alanine (13\%). Histidine, ornithine, citrulline and arginine all account for $6-8 \%$ of free amino acids within $\mathrm{NMF}^{42}$. The data in Fig. 4 show some correlation $\left(R^{2}=0.82\right)$ between increasing bond energies and increasing DRH, suggesting that when amino acids can form strong intermolecular bonds, it is less likely to form intermolecular hydrogen bonds with water.
Recently, amino acids have attracted more attention in the cosmetics market. The estimated market of amino acids for use in cosmetics is 14,000 tons per year ${ }^{43)}$. As described above, amino acid derivatives are used for foaming cleansing agents. From the cosmetic ingredients instructions, arginine was found to be the most used in cosmetics and personal care products, with more than 500 cases being used; more than 400 were used for leave-in preparations. The second most used amount of glycine is a total of 360 kinds of which 252 of them are used for the prepara- 

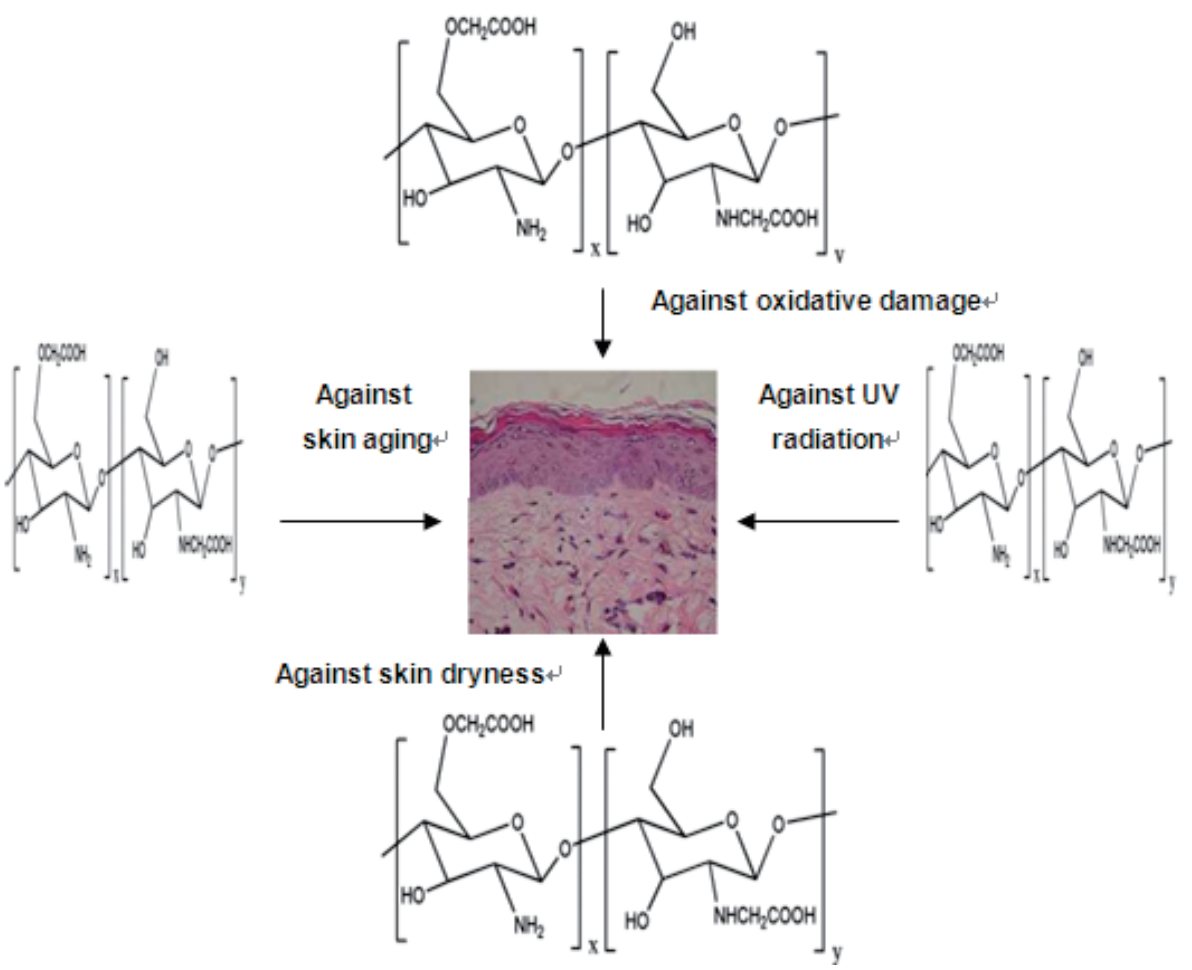

Fig. 5 Carbohydrates prevent skin aging and cutaneous disorders.

tion of no-cleansing ${ }^{44)}$. Pollen contains $10.4 \%$ of essential amino acids such as methionine, lysine, threonine, histidine, leucine, isoleucine, valine, phenylalanine, andtryptophan, thus they have attracted attention for cosmetic applications.

\subsection{Carbohydrates of bee pollen in cosmetics}

Carbohydrates (e.g., alginates, carrageenans, ulvans, fucoidans, laminarans, agar) of bee pollen are mainly used as thickeners, emulsion stabilizers, protective colloids, gelling, moisturizing and chelating agents. They possess anti-oxidative, anti-cellulite, anti-viral, anti-inflammatory and antiaging properties. It can be applied to prevent skin aging and cutaneous disorders (Fig. 5).

2.2.1 Carbohydrates against skin aging

Degeneration of skin tissue can lead to skin aging. Through morphometric examination of skin biopsies it is found that the total skin thickness will be lost by about 7\% every 10 years. Fodil-Bourahla proved that L-fucose can effectively promote the increase of skin thickness and densify collagen. Other findings indicate that 3H-L-fucose penetrates into the dermis and can produce more pronounced results. L-fucose and fucose-rich oligosaccharides and polysaccharides (FROP-s) can affect collagen biosynthesis and accumulation in fibroblasts ${ }^{45)}$.

2.2.2 Carbohydrates against ultraviolet B radiation

UVA and UVB reach the skin surface and are partially reflected by the epidermis's stratum corneum and absorbed by epidermal melanin. However, a large amount of radia- tion is not reflected inside the skin and induces damage to DNA and other skin cells, which greatly increases the incidence of skin cancer. Studies have found that the use of Cordyceps sinensis polysaccharides can prevent UVB-induced cyclobutane-pyrimidine dimer (CPD) formation. After 24 hours of pretreatment with Cordyceps polysaccharide, the CPD content of irradiated cells was also significantly reduced ${ }^{46)}$.

\subsubsection{Carbohydrates against oxidative damage}

Skin is one of the most frequently exposed tissues to oxidative stress from exogenous and endogenous sources. Reactive oxygen species (ROS) are the cause of various skin diseases, such as skin cancer, skin autoimmune diseases, xeroderma pigmentosis and skin aging. Currently, studies have found that polysaccharides have the effect of scavenging free radicals and are increasingly used as antioxidants to prevent oxidative damage in food $^{47)}$ and living organisms $^{48)}$. Experiments have found that polysaccharides in black fungus can significantly reduce the skin malondialdehyde (MDA), lipofuscin (LF) content and enhance the activity of superoxide dismutase (SOD) ${ }^{49)}$.

\subsubsection{Carbohydrates against skin dryness}

Moisturizing of the skin is recognized as the first anti-aging skin care. Cosmetics and skin care products have a certain moisturizing effect. With aging and prolonged exposure of the skin, tissues with moisturizing effects in the skin can be damaged. Natural polysaccharides, mainly from natural or biotechnological origin, were proposed as external moisturizing agents. These natural polysaccharides, 
known to capture humidity on the skin's surface after integration in topical formulations, are very useful to increase skin hydration in dry environments such as winter or airconditioned rooms. Hyaluronic acid (HA), a common mucopolysaccharide is an important functional ingredient in cosmetics and in clinical medicine because of its excellent moisture-retention ability ${ }^{50)}$. Li et al. reported good moisture retention activity of the polysaccharide from Nostoc commune $^{51)}$. Xylose, a sugar and a component of natural glycosaminoglycanes, has also been shown to be a keratinocyte HA synthesis stimulating agent and skin hydrating agent $^{52)}$.

\subsection{Lipids of bee pollen in cosmetics}

Recent studies suggest that supplementing intercellular lipids of the stratum corneum can enhance the functioning of the skin. In the epidermis, lipids of bee pollen are crucial ingredients that allow us to form the permeability barrier that prevents the movement of water and electrolytes through the stratum corneum that is essential for life. Extracutaneous lipids also make a significant contribution to the formation and maintenance of a normal permeability barrier. And topical treatment with lipids can improve permeability barrier function and treat cutaneous disease.

2.3.1 Glycolipids by bee pollen

Studies have shown that supplementing the intercellular lipids of the stratum corneum can improve the protective function of the skin. In the epidermis, lipids are key substances that make the skin a permeable barrier that blocks the penetration of water and electrolytes through the stratum corneum, which is an important part of skin metabolism. Subcutaneous lipids also make a significant contribution to the formation and maintenance of normal permeability barriers. And topical treatment with lipids can improve permeability barrier function and treat skin diseases $^{53,54)}$.

\subsubsection{Effect of Lipopeptides}

Lipopeptides are biosurfactants extensively used in cosmetics. Due to its unique surface activity, it has been made into various forms of cosmetics. It was found to be an amphiphilic cyclic polypeptide consisting of 7-10 amino acids (Fig. 6). In addition to their anti-wrinkle, moisturizing and

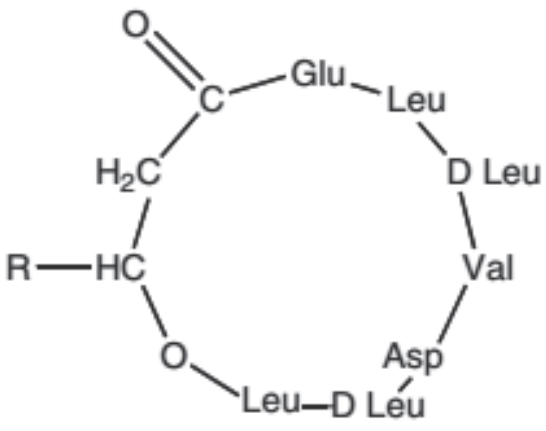

(A)

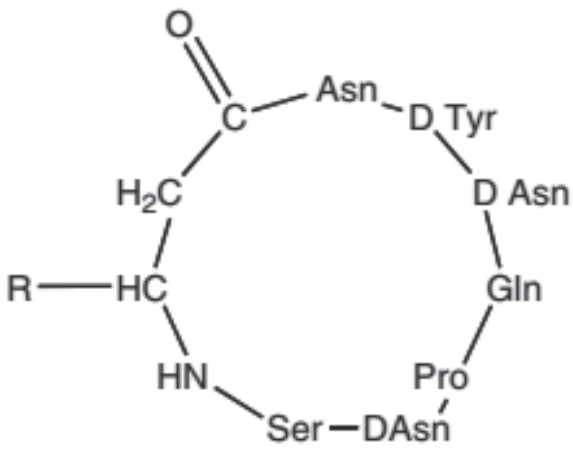

(B)



(C)

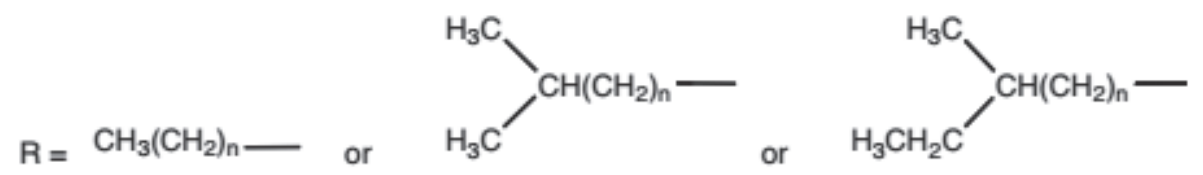

Fig. 6 Primary structure of Lipopeptides, $\operatorname{surfactin}(\mathrm{A})$, iturin $(\mathrm{B})$ and fengycin $(\mathrm{C})^{55,56)}$. 
cleansing properties, their broad spectrum of anti-bacterial and fungal activity has also been demonstrated, and as a result, lipopeptides in this bee pollen have also been more developed potential ${ }^{55,56)}$.

\subsubsection{Polyunsaturated fatty acids (PUFA)}

The importance of polyunsaturated fatty acids (PUFAs) in human skin health is increasingly favored by people, and the protective effect of PUFAs on the skin has received much attention. Studies have shown that n-3 PUFA can reduce the sensitivity of human skin to radiation. According to reports, fish oil is a natural rich source of EPA and DHA, which can reduce UVR-induced erythema in human skin $^{57)}$. As shown in Fig. 7. Polyunsaturated fatty acids can regulate lipid metabolism and inflammation by binding to nuclear transcription factors such as NFB, AP-1 and sterol regulatory element binding protein $(\mathrm{SREBP})$ and receptors including peroxisome proliferator-activated receptor (PPAR). Related Genes, Liver X and Retinoid X Receptors $^{58)}$

\subsection{Vitamins of bee pollen in cosmetics}

Vitamins are increasingly used in $\operatorname{cosmetics}^{59)}$. It is believed that the extra use of vitamins from bee pollen in cosmetics can better protect and possibly correct damage by neutralizing free radicals. In addition, some vitamins may be beneficial to the skin because other effects such as inhibiting pigmentation and bruising, stimulate collagen production, improve keratinization or anti-inflammatory effects.

2.4.1 The value of vitamin A from bee pollen in cosmetics

In recent years, vitamin $\mathrm{A}$ and its derivatives and $\beta$-carotene (provitamin A) have been widely used in cosmetics. The main feature of vitamin A and its derivatives in cosmetics is the ability to normalize keratinization. Vitamin A (retinol and retinyl ester) has a strong absorption peak in ultraviolet(UV) radiation between 300 and $350 \mathrm{~nm}$ with a maximum of $325 \mathrm{~nm}$, which is the visible wavelength range. In addition to being a precursor of the biologically active form of epidermal vitamin A with photocarcinogenic properties, epidermal retinyl esters also help protect DNA from UV-induced changes in the sequence ${ }^{60)}$.

2.4.2 The value of vitamin $\mathrm{C}$ from bee pollen in cosmetics

The main cause of skin aging is light and the environment consumes a large amount of vitamin $\mathrm{C}$ in the body. Even if the minimum UV exposure is 1.6, the minimum erythema dose (MED) will significantly reduce vitamin $\mathrm{C}$ levels ${ }^{61)}$. Therefore, increasing the content of vitamin $\mathrm{C}$ in the skin is an important factor in delaying skin aging, and secondly, it may also be very beneficial as a topical administration of medicinal cosmetics.

2.4.3 The value of vitamin $\mathrm{E}$ from bee pollen in cosmetics

In the skin, vitamin $\mathrm{E}$ is especially abundant in the stratum corneum, delivered there by sebum. Topical vitamin $\mathrm{E}$ has been used effectively to treat melasma and pigmented contact dermatitis, as demonstrated in one multiclinical doubleblind study. Clinically, topical vitamin E does decrease wrinkles and solar lentigoes of photoaging. Microscopic examination showed correction of the UV-induced epidermal hypertrophy, thickened stratum corneum, increased "sunburn cells" in the basal layer, and disruption of dermal collagen. Further electron microscopic analysis confirmed correction of collagen and elastin fiber damage



Fig. 7 Proposed mode of action of n-3 PUFA such as EPA on UVR-induced signalling events related to acute UNR-induced cutaneous inflammation (sunburn) ${ }^{59)}$. 
and demonstrated repair of UV-induced disruption of the basement membrane anchoring fibrils ${ }^{62,63)}$.

\subsubsection{Vitamin $\mathrm{B}_{3}$ by bee pollen}

Vitamin $\mathrm{B}_{3}$, also known as nicotinamide, is a niacin derivative obtained from the diet. Bee pollen contains a lot of vitamin $\mathrm{B}_{3}$. The coenzyme nicotinamide adenine dinucleotide (NAD), NAD phosphate (NADP), is a component of nicotinamide and its reduced forms are NADH and NADPH. Niacinamide is one of the widely used vitamins in pharmaceutical cosmetics. Most of the existing studies have antiinflammatory and anti-acne effects ${ }^{64)}$. A small amount of nicotinamide improves the skin's appearance of sphingolipids, free fatty acids, and also has a certain correlation in the synthesis of cholesterol and ceramide, thereby reducing transepidermal water loss ${ }^{65)}$.

\subsection{Polyphenolics from bee pollen in cosmetics}

Polyphenols are a large class of phytochemicals found in many edible and medicinal plants. The chemical structure of polyphenolic compounds causes their reducing properties, which allow them to act as antioxidants and free radical scavengers. So they are of great interest to manufacturers of cosmetic and cosmeceutical products ${ }^{66)}$. Studies have found that pure natural polyphenols (such as green tea polyphenols (GTP), mainly derived from milk chrysin silymarin and grape seed (GSP) procyanidins) can effectively control UV radiation-induced inflammation, oxidative stress, DNA damage and immune response(Table 3).
2.5.1 Photoprotective properties of polyphenols by bee pollen

The photoprotective properties of polyphenols can be measured, when treated skin area is irradiated with UV light and the resulting erythema is appraised. Polyphenol extracts from pistachio nut significantly reduced UVB-induced skin erythema by topical application in human volunteers $^{67)}$. Polyphenols have a role in the prevention of UV irradiation. It has been found that water-extracting polyphenols in green tea leaves can effectively prevent the occurrence of UV-induced tumors $^{68)}$. The application of chemopreventive constituent in green tea, ( - ) -epigallocatechin-3-gallate (EGCG) may prove helpful in ameliorating the harmful effects caused by UVB exposure through decreased ROS production(Fig. 8).

2.5.2 Anti-inflammatory effects of polyphenols

UV-induced cyclooxygenase-2 (COX-2) expression and the increase in prostaglandin $(\mathrm{PG})$ metabolites in the skin are characteristic responses of keratinocytes to acute or chronic skin sensitization. It has been reported that treatment with green tea polyphenols can inhibit the UV radiation-induced expression of COX-2 and its PG metabolites $^{69)}$. Topical application of EGCG can inhibit the production of UV-induced PG metabolites. PGE metabolites include $\mathrm{PGE}_{2}, \mathrm{PGF}_{2 \alpha}$ and $\mathrm{PGD}_{2}$, which play an important role in inflammatory diseases and proliferative skin diseases. A possible pathway for polyphenols to interfere with inflammatory responses is their ability to inhibit the activation of transcription factors $\mathrm{NF}-\kappa \mathrm{B}$ and $\mathrm{AP}-1$, which regulate the secretion of pro-inflammatory cytokines (TNF- $\alpha$, IL-1, IL-6, IL-8) (Fig. 9).

Table 3 Polyphenols: their sources, molecular structures and the mechanism of action in skin photoprotection.

\begin{tabular}{lll}
\hline Polyphenolics & Major source
\end{tabular}




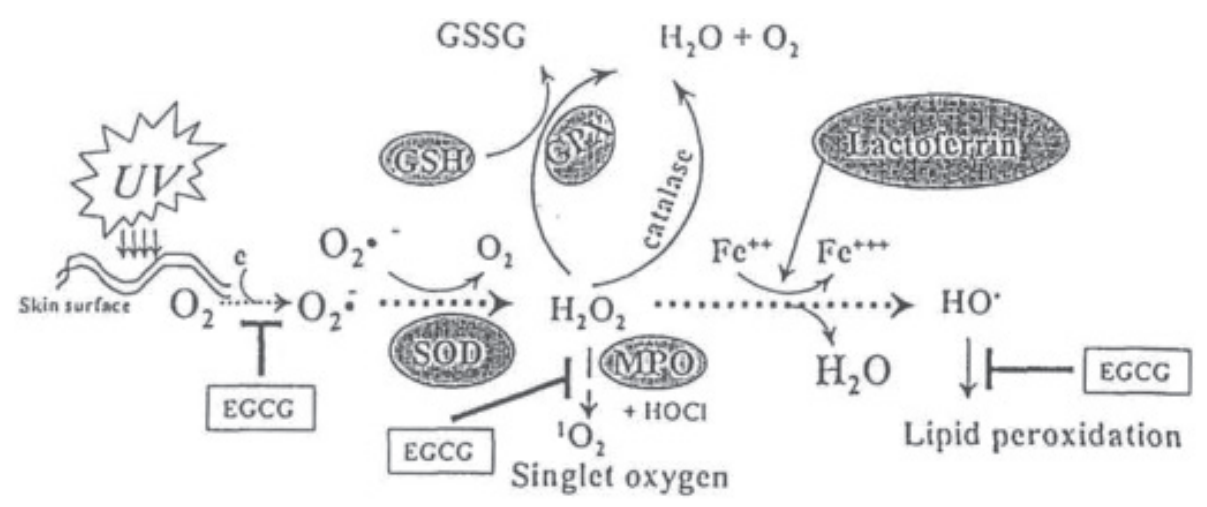

Fig. 8 Sites of action of EGCG, which may be responsible for reduction in the UV-induced oxidative stress in the skin, are shown by blocking heads ${ }^{66)}$.

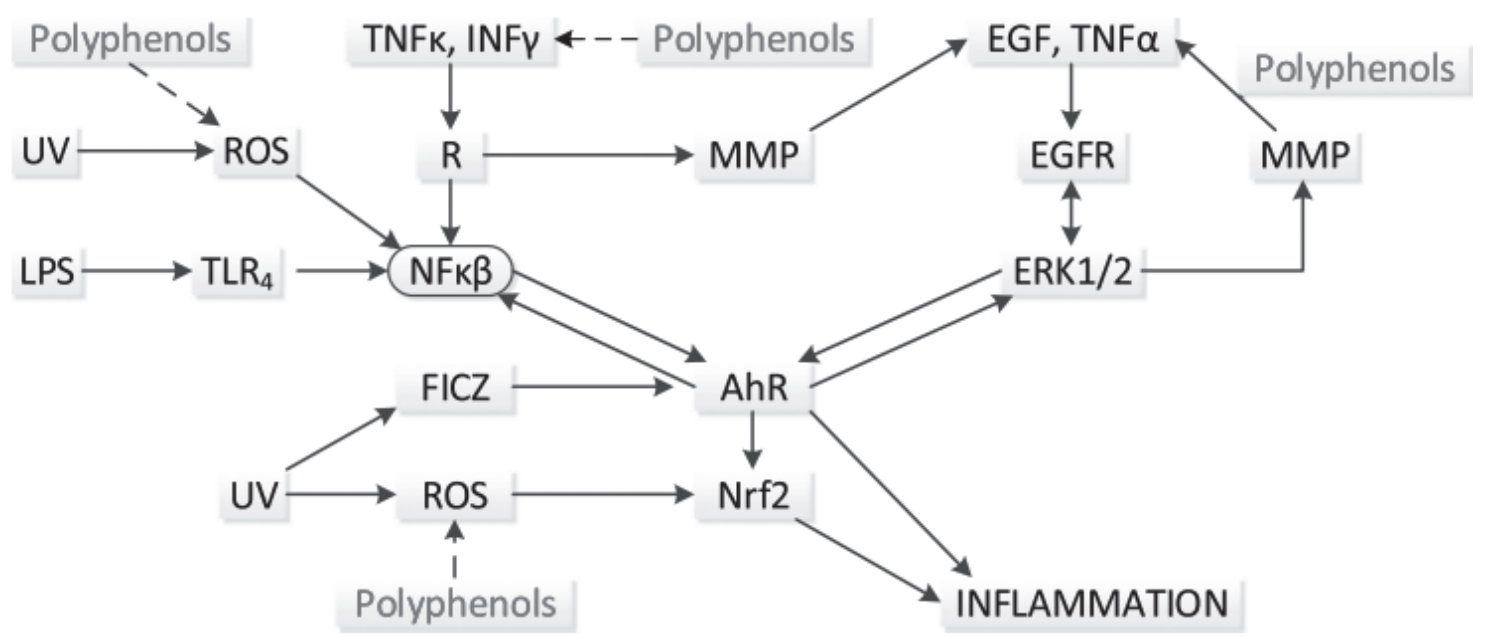

Fig. 9 Inhibition of inflammation inducing factors in the skin by polyphenols ${ }^{71)}$.

2.5.3 Skin-lightening effects of polyphenols from bee pollen

Most women want to maintain by improving skin color and reducing the appearance of pigmentation spots ("age" or "sun" spots). Traditional pigmentation agents, such as hydroquinone, work well for a long time ${ }^{71)}$. However, natural resources and extracts represent a library of ingredients that can be used for topical treatment to improve hyperpigmentation and the overall appearance of the skin. Many types of polyphenol plant extracts have been observed to inhibit melanogenesis. Ellagic acid extracted from pomegranate peel showed inhibitory activity against mushroom tyrosinase in vitro ${ }^{72)}$. Oral administration of crude polyphenol concentrate extracts from etholob effectively reduced pigmented skin in guinea pigs.

This effect may be mainly by inhibiting tyrosinase activity in melanocytes to inhibit melanin synthesis ${ }^{73)}$. Kuwanon $\mathrm{O}$ and Sanggenon $\mathrm{T}$ are two potential skin whitening ingredients in $M$. astralis root extracts. They were found to have decolorization in mouse b16 and melan-a cell lines ${ }^{74)}$. Although polyphenols are widely regarded as an effective whitening substance, verification of clinical trials is still needed.

\section{Discussion}

There is a long history of the recorded use of bee pollen by humans. Around $70 \%$ of substances in bee pollen are biologically active, such as proteins, carbohydrates, lipids and fatty acids, phenolic compounds, vitamins and bioelements. As a natural bee product, bee pollen may effectively enhance protective mechanisms against skin aging, skin dryness, ultraviolet $\mathrm{B}$ radiation, oxidative damage, inflammatory and melanogenesis, which are involved in a wide range of negative effects on human skin, thus they have attracted attention for health and cosmetic applications. By learning about the cosmeceutical properties of bee pollen and the mechanism of its active components action, its beneficial influence on human skin can be embraced. 


\section{Conflict of interest}

The authors declare no conflicts of interest.

\section{Reference}

1) Campos, M.G.R.; Bogdanov, S.; Almeida-Muradian, L.B.D. et al. Pollen composition and standardisation of analytical methods. J. Apic. Res. 47, 154-161 (2008).

2) Campos, M.; Frigerio, C.; Lopes, J.; Bogdanov, S. What is the future of bee-pollen? J. Api. Prod. Api. Med. Sci. 2, 131-144(2010).

3) Campos, M.; Markham, K.R.; Mitchell, K.A.; Cunha, A.P.D. An approach to the characterization of bee pollens via their flavonoid/phenolic profiles. Phytochem. Anal. 8, 181-185(1997).

4) Pascoal, A.; Rodrigues, S.; Teixeira, A.; Feás, X.; Estevinho, L.M. Biological activities of commercial bee pollens: antimicrobial, antimutagenic, antioxidant and anti-inflammatory. Food Chem. Toxicol. 63, 233-239 (2004).

5) Middleton, E.Jr. Effect of plant flavonoids on immune and inflammatory cell function. Adv. Exp. Med. Biol. 439, 175-182 (1998).

6) Rzepecka-Stojko, A.; Pilawa, B.; Ramos, P.; Stojko, J. Antioxidative properties of bee pollen extracts examined by EPR spectroscopy. J. Apic. Sci. 56, 23-31 (2012).

7) Tomas-Lorente, F.; Garciagrau, M.M.; Nieto, J.L.; Tomas-Barberan, F.A. Flavonoids from Cistus-Ladanifer bee pollen. Phytochemistry 31, 2027-2029 (1992).

8) Choi, E-M. Antinociceptive and antiinflammatory activities of pine (Pinus densiflora) pollen extract. Phytother. Res. 21, 471-475 (2007).

9) Diplock, A.T.; Charleux, J.L.; Crozier-Willi, G.; Kok, F.J.; Rice-Evans, C.; Roberfroid, M. et al. Functional food science and defence against reactive oxidative species. Br. J. Nutr. 80, 77-112 (1998).

10) Nakajima, Y.; Tsuruma, K.; Shimazawa, M.; Mishima, S.; Hara, $\mathrm{H}$. Comparison of bee products based on assays of antioxidant capacities. BMC Comp. Altern. Med. 9, 4 (2009).

11) Campos, M.G.; Webby, R.F.; Markham, K.R.; Mitchell, K.A.; Da Cunha, A.P. Age-induced diminution of free radical scavenging capacity in bee pollens and the contribution of constituent flavonoids. J. Agric. Food Chem. 51, 742-745 (2003).

12) Wu, Y.D.; Lou, Y.J. A steroid fraction of chloroform extract from bee pollen of Brassica campestris induces apoptosis in human prostate cancer PC-3 cells. Phytother. Res. 21, 1087-1091 (2007).

13) Erkmen, O.; Özcan, M.M. Antimicrobial effects of Turkish propolis, pollen, and laurel on spoilage and pathogenic food-related microorganisms. J. Med.
Food. 11, 587-592(2008).

14) Dudov, I.A. Antioxidant system of rat erythrocytes under conditions of prolonged intake of honeybee flower pollen load. Ukr. Biokhim. Zh. 66, 94-96 (1994).

15) Ishikawa, Y.; Tokura, T.; Nakano, N.; Hara, M.; Niyonsaba, F.; Ushio, H. et al. Inhibitory effect of honeybeecollected pollen on mast cell degradation in vivo and in vitro. J. Med. Food 11, 14-20 (2008).

16) Polański, M.; Okoń, K.; Przybyło, R.; Frasik, W. Cardioprotective properties of hydrophilic pollen extract (HPE). Pol. J. Pathol. 49, 109-112(1998).

17) Samochowiec, L.; Wójcicki, J. Effect of pollen on serum and liver lipids in rats fed on a high-lipid diet. Herba Polon. 27, 333 (1981).

18) Yakusheva, E. Pollen and bee bread; physico-chemical properties. Biological and pharmacological effects. Use in medical practice. in Theoretical and Practical Basics of Apitherapy (Rakita, D.; Krivtsov, N.; Uzbekova, D.G. eds.), Roszdrav, Ryazan, Russia, pp. 84-97 (2010).

19) Machoy-Mokrzyńska, A.; Łoniewski, I.; Wojcicki, J. Infuence of pollen extracts on the central nervous system. Herba Polon. 38, 189 (1992).

20) Florek, E.; Leciejewska, A. Próba zastosowania preparatów pszczelarskich w profilaktyce zatruć tri chloroetylenem. Herba Polon. 41, 70 (1995).

21) Manning, R. Fatty acids in pollen: a review of their importance for honey bees. Bee World 82, 60-75 (2001).

22) Juźwiak, S.; Samochowiec, L.; Wójcicki, J. The influence of pollen extracts on serum trigliceride lipase activity in rabbits fed with a high-fat diet. Herba Polon. 35, 43 (1989).

23) Oliveira, K.C.L.S.; Moriya, M.; Azedo, R.A.B. et al. Relationship between botanical origin and antioxidants vitamins of bee-collected pollen. Qurímica Nova 32, 1099-1102 (2009).

24) Attia, Y.A.; Al-Hanoun, A.; El-Din, A.E. et al. Effect of bee pollen levels on productive, reproductive and blood traits of NZW rabbits. J. Anim. Physiol. Anim. Nutr. (Berl.) 95, 294-303 (2011).

25) Khalil, F.A.; El-Sheikh, N.M. The effects of dietary Egyptian propolis and bee pollen supplementation against toxicity if sodium fluoride in rats. Am. J. Sci. 11, 310-316 (2010).

26) Roulston, T.H.; Cane, J. H. Pollen nutritional content and digestibility for animals. Plant Syst. Evol. 222, 187-209 (2000).

27) Kędzia, B.; Hołderna-Kędzia, E. Biological properties and therapeutic action of bee pollen. Postepy. Fitoterapii 3-4, 103-108(2005).

28) Kędzia, B.; Hołderna-Kędzia, E. New studies on biological properties of pollen. Postepy Fitoterapii 1, 48-54 (2012).

29) Almeida-Muradian, L.B.; Pamplona, L.C.; Coimbra, S.; 


\section{Bee Pollen in Cosmetic}

Barth, O.M. Chemical composition and botanical evaluation of dried bee pollen pellets. J. Food Compost. Anal. 18, 105-111 (2005).

30) Szczesna, T. Long chain fatty acids composition of honeybee-collected pollen. J. Api. Sci. 50, 65-79 (2006).

31) Asafova, N.; Orlov, B.; Kozin, R. Physiologically Active Bee Products (Nikolaev, Y.A. ed.). Nizhny Novgorod, Russia (2001).

32) Campos, M.G.R.; Bogdanov, S.; Almeida-Muradian, L.B.de. et al. Pollen composition and standardisation of analytical methods. J. Api. Res. 47, 154-161 (2008).

33) Campos, M.; Firgerio, C.; Lopes, J.; Bogdanov, S. What is the future of Bee-Pollen? J. Anal. At. Spectrom. 2, 131-144(2010).

34) Vígh, L.; Literáti, P.N.; Horváth, I. et al. Bimoclomol: a nontoxic, hydroxylamine derivative with stress protein-inducing activity and cytoprotective effects. Nat. Med. 3, 1150-1154(1997).

35) Turowski, A; Adlmann-Grill, B.C. Substantivity to hair and skin of 125-labelled collagen hydrolysates under application simulating conditions. Int. J. Cosmet. Sci. 7, 71-74(1985).

36) Adler-Nissen, J. Enzymatic hydrolysis of food proteins. Elsevier Applied Science Publishers, UK (1986).

37) Mac-Mary, S.; Sainthillier, J.M.; Jeudy, A.; Sladen, C.; Williams, C.; Bell, M.; Humbert, P. Assessment of cumulative exposure to UVA through the study of asymmetrical facial skin aging. Clin. Interv. Aging 5, 277 (2009).

38) Korbee, N.; Figueroa, F.L.; Aguilera, J. Accumulation of mycosporine-like amino acids (MAAs) : biosynthesis, photocontrol and ecophysiological functions. Rev. Chil. Hist. Nat. 79, 119-132(2006).

39) Oyamada, C.; Kaneniwa, M.; Ebitani, K.; Murata, M.; Ishihara, K. Mycosporine-like amino acids extracted from scallop (Patinopecten yessoensis) ovaries: UV protection and growth stimulation activities on human cells. Mar. Biotechnol. (NY) 10. 141-150(2008).

40) Chen, H.; Weng, Q.Y.; Fisher, D.E. UV signaling pathways within the skin. J. Invest. Dermatol. 134, 20802085 (2014).

41) Ohta, R.; Ino, M. Composition of NMF in human stratum corneum and its permeability and moisturizing behavior. Bio Industry 22, 31-37 (2005).

42) Burke, R.C. Free amino acids and water soluble peptides in stratum corneum and skin surface film in human beings. Yale J. Biol. Med. 38, 355-373 (1996).

43) The experimental bond energies an article containing tables summarizing the results of the calculated experimental parameters of 800 exemplary solved molecules found in The Grand Theory of Classical Physics. Available at: http://www.blacklightpower.-com/theory/ bookdownload.shtml, accessed January 15(2015).
44) FDA. Frequency of Use of Cosmetic Ingredients. FDA Database. Washington, DC: FDA; Data received May 16, 2012 via a Freedom of Information Act request (2012).

45) Fodil-Bourahla, I.; Bizbiz, L.; Robert, A.M.; Robert, L. Effects of L-fucose and fucose-rich oligo- and polysaccharides (FROP-s) on biosynthesis by human skin fibroblasts. Modulation of the effect of retinol, ascorbate and a-tocopherol. Biomed. Pharmacother. 57, 187194 (2003).

46) Wong, W.C.; Wu, J.Y.; Benzie, I.F. Photoprotective potential of Cordyceps polysaccharides against ultraviolet $B$ radiation-induced DNA damage to human skin cells. Benzie. Br. J. Dermatol. 164, 980-986(2011).

47) Kim, K.W.; Thomas, R.L. Antioxidative activity of chitosans with varyingmolecular weights. Food Chem. 101, 308-313 (2007).

48) Jeon, T.I.; Hwang, S.G.; Park, N.G.; Jung, Y.R. Antioxidative effect of chitosan on chronic carbon tetrachloride induced hepatic injury. Toxicology 187, 67-73 (2003).

49) Peng, X.-B.; Li, Q.: Ou, L.-N. et al. GC-MS, FT-IR analysis of black fungus polysaccharides and its inhibition against skin aging in mice. Int. J. Biol. Macromol. 47, 304-307 (2010).

50) Sakai, S.; Yasuda, R.; Sayo, T.; Ishikawa, O.; Inoue, S. Hyaluronan exists in the normal stratum corneum. $J$. Invest. Dermatol. 114, 1184-1187 (2000).

51) Li, L.Y.; Jiang, X.L.; Guan, H.S.; Wang, P.; Guo, H. Three alginate lyases from marine bacterium Pseudomonas fluorescens HZJ216: purification and characterization. Appl. Biochem Biotechnol. 164, 305-317 (2011).

52) Dumas, M.; Gondran, C.; Senechal, E.; Bonté, F. Stimulation of glycosaminoglycan synthesis in Keratinocytes by D Xylose. J. Invest. Dermatol. 113, 457 (1999).

53) Banat, I.; Makkar, R.; Cameotra, S. Potential commercial applications of microbial surfactants. Appl. Microbiol. Biotechnol. 53, 495-508(2000).

54) Benincasa, M.; Abalos, A.; Oliveria, I.; Manresa, A. Chemical structure, surface properties and biological activities of the biosurfactant produced by Pseudomonas aeruginosa LBI from soapstock. Antonie Van Leeuwenhoek 85, 1-8(2004).

55) Hwang, Y.H.; Park, B.K.; Lim, J.H. et al. Lipopolysaccharide-binding and neutralizing activities of surfactin C in experimental models of septic shock. Eur. J. Pharmacol. 556, 166-171(2007).

56) Takahashi, T.; Ohno, O.; Ikeda, Y. et al. Inhibition of lipopolysaccharide activity by a bacterial cyclic lipopeptides surfactin. J. Antibiot. 59, 35-43(2006).

57) Jin, X.J.; Kim, E.J.; Oh, I.K.; Kim, Y.K.; Park, C.H.; Chung, J.H. Prevention of UV induced skin damages by 11,14,17-eicosatrienoic acid in hairless mice in 
vivo. J. Korean Med. Sci. 25, 930-937 (2010).

58) Mantovani, A. Molecular pathways linking inflammation and cancer. Curr. Mol. Med. 10, 369-373 (2010).

59) Nicolaou, A.; Pilkington, S.M.; Rhodes, L.E. Ultravioletradiation induced skin inflammation: dissecting the role of bioactive lipids. Chem. Phys. Lipids 164, 535543 (2011).

60) Murray, J.C.; Burch, J.A.; Streilein, R.D. et al. A topical antioxidant solution containing vitamins $\mathrm{C}$ and $\mathrm{E}$ stabilized by ferulic acid provides protection for human skin against damage caused by ultraviolet irradiation. J. Am. Acad. Dermatol. 59, 418-425 (2008).

61) Lin, F.H.; Lin, J.Y.; Gupta, R.D. et al. Ferulic acid stabilizes a solution of vitamins $\mathrm{C}$ and $\mathrm{E}$ and doubles its photoprotection of skin. J. Invest Dermatol. 125, 826832 (2005).

62) Wulf, H.C.; Stender, I.M.; Lock-Andersen, J. Sunscreens used at the beach do not protect against erythema: a new definition of SPF is proposed. Photodermatol. Photoimmunol. Photomed. 13, 129-132 (1997).

63) Haywood, R.; Wardman, P.; Sanders, R.; Linge, C. Sunscreens inadequately protect against ultraviolet A-induced free radicals in skin: implications for skin aging and melanoma? J. Invest Dermatol. 121, 862-868 (2003).

64) Berson, D.S.; Chalker, D.K.; Harper, J.C. et al. Current concepts in the treatment of acne: report from a clinical roundtable. Cutis 72, 5-13(2003).

65) Griffiths, C.E.M. Nicotinamide $4 \%$ gel for the treatment of inflammatory Acne vulgaris. J. Dermatol. Treat. 6, S8-S10 (1995).

66) Katiyar, S.K.; Elmets, C.A. Green tea polyphenolic antioxidants and skin photoprotection(Review). Int. J. Oncol. 18, 1307-1313(2001).
67) Martorana, M.; Arcoraci, T.; Rizza, L. et al. In vitro antioxidant and in vivo photoprotective effect of pistachio (Pistacia vera L.,variety Bronte) seed and skin extracts. Fitoterapia 85, 41-48(2013).

68) Wang, Z.Y.; Huang, M.T.; Ferraro, T. et al. Inhibitory effect of green tea in the drinking water on tumorigenesis by ultraviolet light and 12-O-tetradecanoylphorbol-13-acetate in the skin of SKH-1 mice. Cancer Res. 52, 1162-1170 (1992).

69) Meeran, S.M.; Akhtar, S.; Katiyar, S.K. Inhibition of UVB-induced skin tumor development by drinking green tea polyphenols is mediated through DNA repair and subsequent inhibition of inflammation. J. Invest. Dermatol. 129, 1258-1270 (2009).

70) Katiyar, S.K.; Matsui, M.S.; Elmets, C.A. et al. Polyphenolic antioxidant $(-)$-epigallocatechin-3-gallate from green tea reduces UVB-induced inflammatory responses and infiltration of leukocytes in human skin. Photochem. Photobiol. 69, 148-153(1999).

71) Ratzłyko, A.; Arct, J.; Majewski, S.; Pytkowska, K. Influence of polyphenols on the physiological processes in the skin. Phytother. Res. 29, 509-517(2015).

72) Yoshimura, M.; Watanabe, Y.; Kasai, K.; Yamakoshi, J.; Koga, T. Inhibitory effect of an ellagic acid-rich pomegranate extract on tyrosinase activityand ultravioletinduced pigmentation. Biosci. Biotechnol. Biochem. 69, 2368-2373 (2005).

73) Hanamura, T.; Uchida, E.; Aoki H. Skin-lightening effect of a polyphenol extract from Acerola (Malpighia emarginata DC.) fruit on UV-induced pigmentation. Biosci. Biotechnol. Biochem. 72, 3211-3218(2008).

74) Hu, S.; Zheng, Z.; Chen, F.; Wang M. The depigmenting effect of natural resorcinol type polyphenols Kuwanon $\mathrm{O}$ and Sanggenon $\mathrm{T}$ from the roots of morus australis. J. Ethnopharmacol. 195, 196-203 (2017). 